\title{
Canopy cover or remotely sensed vegetation index, explanatory variables of above-ground biomass in an arid rangeland, Iran
}

\author{
Fatemeh PORDEL ${ }^{1}$, Ataollah EBRAHIMI ${ }^{1 *}$, Zahra AZIZI $^{2}$ \\ ${ }^{1}$ Department of Range and Watershed Management, Shahrekord University, Shahrekord 8818634141, Iran; \\ ${ }^{2}$ Department of RS-GIS, Science and Research Branch, Islamic Azad University, Tehra 1477893855, Iran
}

\begin{abstract}
Estimation of above-ground biomass is vital for understanding ecological processes. Since direct measurement of above-ground biomass is destructive, time consuming and labor intensive, canopy cover can be considered as a predictor if a significant correlation between the two variables exists. In this study, relationship between canopy cover and above-ground biomass was investigated by a general linear regression model. To do so, canopy cover and above-ground biomass were measured at 5 sub-life forms (defined as life forms grouped in the same height classes) using 380 quadrats, which is systematic-randomly laid out along a 10-km transect, during four sampling periods (May, June, August, and September) in an arid rangeland of Marjan, Iran. To reveal whether obtained canopy cover and above-ground biomass of different sampling periods can be lumped together or not, we applied a general linear model (GLM). In this model, above-ground biomass was considered as a dependent or response variable, canopy cover as an independent covariate or predictor factor and sub-life forms as well as sampling periods as fixed factors. Moreover, we compared the estimated above-ground biomass derived from remotely sensed images of Landsat- 8 using NDVI (normalized difference vegetation index), after finding the best regression line between predictor (measured canopy cover in the field) and response variable (above-ground biomass) to test the robustness of the induced model. Results show that above-ground biomass (response variable) of all vegetative forms and periods can be accurately predicted by canopy cover (predictor), although sub-life forms and sampling periods significantly affect the results. The best regression fit was found for short forbs in September and shrubs in May, June and August with $\mathrm{R}^{2}$ values of $0.96,0.93$ and 0.91 , respectively, whilst the least significant was found for short grasses in June, tall grasses in August and tall forbs in June with $R^{2}$ values of $0.71,0.73$ and 0.75 , respectively. Even though the estimated above-ground biomass by NDVI is also convincing $\left(R^{2}=0.57\right)$, the canopy cover is a more reliable predictor of above-ground biomass due to the higher $R^{2}$ values (from 0.75 to 0.96 ). We conclude that canopy cover can be regarded as a reliable predictor of above-ground biomass if sub-life forms and sampling periods (during growing season) are taken into account. Since, (1) plant canopy cover is not distinguishable by remotely sensed images at the sub-life form level, especially in sparse vegetation of arid and semi-arid regions, and (2) remotely sensed-based prediction of above-ground biomass shows a less significant relationship $\left(R^{2}=0.57\right)$ than that of canopy cover $\left(R^{2}\right.$ ranging from 0.75 to 0.96$)$, which suggests estimating of plant biomass by canopy cover instead of cut and weighting method is highly recommended. Furthermore, this fast, nondestructive and robust method that does not endanger rare species, gives a trustworthy prediction of above-ground biomass in arid rangelands.
\end{abstract}

Keywords: rangeland; biomass; non-destructive method; arid ecosystems; NDVI

\footnotetext{
*Corresponding author: Ataollah EBRAHIMI (E-mail: Ataollah.Ebrahimi@sku.ac.ir)

Received 2017-05-16; revised 2018-04-12; accepted 2018-05-07

(C) Xinjiang Institute of Ecology and Geography, Chinese Academy of Sciences, Science Press and Springer-Verlag GmbH Germany, part of Springer Nature 2018
} 
Citation: Fatemeh PORDEL, Ataollah EBRAHIMI, Zahra AZIZI. 2018. Canopy cover or remotely sensed vegetation index, explanatory variables of above-ground biomass in an arid rangeland, Iran. Journal of Arid Land, 10(5): 767-780. https://doi.org/10.1007/s40333-018-0017-y

\section{Introduction}

Above-ground biomass is the amount of vegetative parts produced or energy stored per unit of area (Sala and Austin, 2000; Flombaum and Sala, 2007). The study of above-ground biomass of rangeland has been a central theme in ecological studies for evaluating their spatial and temporal variations controlled by biotic and abiotic factors (Olofsson et al., 2001; Radloff and Mucina, 2007), and addressed by a range of questions, from livestock forage availability (Di Bella et al., 2005) to global carbon cycle balance (Sala and Austin, 2000), as well as the prediction of global climate change (Li et al., 2014). Therefore, accurate estimation of above-ground biomass is critical for the management of rangeland, especially when the effects of management decisions need to be predicted (Ebrahimi et al., 2008) or dealt with sustainable management (Snyman, 1998). Different methods have been developed for measurement of above-ground biomass but most common techniques for biomass estimation consist in clipping and weighing a number of representative plots or individuals (Montès, 2009), which is time-consuming and costly, even non-reproducibility over time (Bonham, 2013), and the species being on the brink of extinction are all among the critics against this technique from the economic and scientific point of view (Montès, 2009).

Plant destruction is an important risk, particularly in some ecosystems where the mean density of several preferred species is low (Guevara et al., 2002). This issue is more concerned in arid and semi-arid rangelands where frequently monitoring of vegetation canopy cover via clip and weighting method might cause extinction of rare species in one hand and plant canopy cover doesn't show a strong correlation by derived vegetation indices from remotely sensed images due to sparsity of canopy cover occurrence on the other hand. Hence, we need an accurate, rapid, and reliable nondestructive method of estimating above-ground biomass.

Canopy cover is defined by the Range Inventory Standardization Committee (RISC) as the percentage of ground covered by a vertical projection of the outermost perimeter of the natural spread of foliage of plants, while foliage cover projected aerial parts of vegetation onto the ground (Anderson, 1986), and only takes into account intercepts of leaves or branches.

Non-destructive methods have been developed specifically for shrubberies (Etienne, 1989; Montès et al., 2004; Frank et al., 2005) and grasslands (Thursby et al., 2002; Tackenberg, 2007). For example, canopy cover as an indirect parameter was used to estimate Atriplex verrciferum M. B. and Salsola dendroides Pall. biomass at Gherekhlar region in Marand, Iran (Mokhtariasl and Mesdaghi, 2008). Yang et al. (2017) also successfully developed some allometric models to predict biomass of 12 shrub species in Chinese desert grassland. The results of investigating the relationship between above-ground biomass and indirect variables such as canopy cover, foliage cover, and basal cover in three habitats of grass-shrubland, grassland, and shrubland revealed that both canopy cover and foliage cover have a significant relationship with production in most species (Arzani et al., 2008), if morphological characteristics of the species are taken into account (Adler et al., 2004; N'avar et al., 2004; Foroughbakhch et al., 2005). Although considerable research has been devoted to the relationship between plant production and allometric equation of vegetation parts such as canopy cover ( Foroughbakhch et al., 2005; Arzani et al., 2008; Arzani et al., 2011; Bonham, 2013), rather less attention has been paid to the effects of life-forms and sampling dates on this relationship. Many researchers believe equations set based on the relationship between above-ground biomass and canopy cover gained at a given time could not be generalized to estimate the above-ground biomass in other times (Hughes et al., 1987; Arzani et al., 2011). Hence, these changes in canopy cover might influence its relation with above-ground biomass. Therefore, the present paper aims at addressing partially this complex problem in an arid rangeland.

In addition to ground measurement of vegetation characteristics, remotely sensed data provide opportunity to monitor large surfaces, regularly with comparatively reasonable times and costs 
(Lu et al., 2004; Caprioli et al., 2006). Multi-temporal remotely sensed images can be used to estimate above-ground biomass and its fluctuations from vegetation indices (VIs). Amongst others, Landsat-8 satellite, provides valuable images for investigating land surface features (Ke et al., 2015), more specifically, above-ground biomass. Most researchers calculate NDVI (normalized difference vegetation index) probably the most used VIs in rangeland and forest management (Brinkmann et al., 2011; Migliavacca et al., 2011; Zhu and Liu, 2015). Several researchers have shown that the relationship between vegetation and environmental parameters with VIs can be expressed as an empirical model (Du Plessis, 1999; Drake et al., 2003; Brinkmann et al., 2011; Ji et al., 2012; Porter et al., 2014; Zhu and Liu, 2015). Glenn et al. (2016) predicted accurately above-ground biomass with remotely sensed data in western USA at some life-form and total above-ground biomass levels. Pordel (2015) established some models to depict spatio-temporal changes of above-ground biomass using VIs derived and extrapolated from Landsat- 8 images in Mrajan rangeland, Iran. Comparing the measurement of above-ground biomass in the field with the satellite-based derived above-ground biomass will also reveals pros and cons of these valuable methods that will be also partially deals with in this research. In summary, a central issue in the study of relationship between above-ground biomass and canopy cover or VIs is studying the effects of life-forms and sampling periods that may influence this relationship due to changes in plant composition or phenological stages, an important issue that received few attentions so far. Therefore, we can summarize the objectives of the preset study as: (1) examining whether the relationship between canopy cover (predictor) and above-ground biomass (response) is influenced by sampling periods and sub-life forms or not; (2) fitting the best prediction equation between above-ground biomass using indirect indicator of canopy cover at different sub-life forms and sampling periods; and (3) predicting and comparing above-ground biomass derived from NDVI with the evaluated above-ground biomass by means of indirect explanatory variable of canopy cover.

\section{Materials and methods}

\subsection{Study area}

This study was conducted in the Marjan rangelands of Boroujen County, Iran, which is located at $31^{\circ} 58^{\prime} 51^{\prime \prime} \mathrm{N}$ to $32^{\circ} 08^{\prime} 29^{\prime \prime} \mathrm{N}$ and $51^{\circ} 16^{\prime} 50^{\prime \prime} \mathrm{E}$ to $51^{\circ} 24^{\prime} 38^{\prime \prime} \mathrm{E}$, with a mean elevation of $2200 \mathrm{~m}$ a.s.l. (Fig. 1a). According to the Koppens' classification method (Wang and Overland, 2004), this area has a temperate and cold climate along with warm and dry summers. Long-term mean annual precipitation (1988-2013) was $250 \mathrm{~mm}$, falling mainly in fall and winter with the highest monthly mean precipitation occurring in December $(48.8 \mathrm{~mm})$ and January $(48.1 \mathrm{~mm})$ and the lowest in Augusts $(0.3 \mathrm{~mm})$ and September $\left(0.6 \mathrm{~mm}\right.$; Fig. 1b). The study area is approximately $7830 \mathrm{hm}^{2}$. Some dominant plant species, along with their family and sub-life forms are presented in Table 1.

\subsection{Methods}

\subsubsection{Field measurements of canopy cover and above-ground biomass}

Canopy cover (i.e., outermost perimeter of the plants) and above-ground biomass were estimated using 95 quadrats at 19 sampling sites (each contains 5 quadrates, with 1 centroid quadrat and 4 quadrates positioned on the four directional corners with 5-m intervals from the central quadrat), the so called sampling nodes, that systematic-randomly distributed along a $10-\mathrm{km}$ transect (the first node was selected systematically but the rests were randomly distributed along the transect) (Fig. 2). The aforementioned measurements were repeated for 4 sampling periods during spring and summer seasons in 2015 (i.e., May, June, August, and September), which made 380 sampling quadrates in total. Following the method of Tahmasebi et al. (2012), a $2 \mathrm{~m} \times 2 \mathrm{~m}$ quadrate size was chosen for estimating canopy cover and above-ground biomass. Canopy cover and above-ground biomass were measured at 5 sub-life form levels, defined as the morphologically similar species from the same vegetation stratum (height class) (Ebrahimi et al., 2008). 
(a)

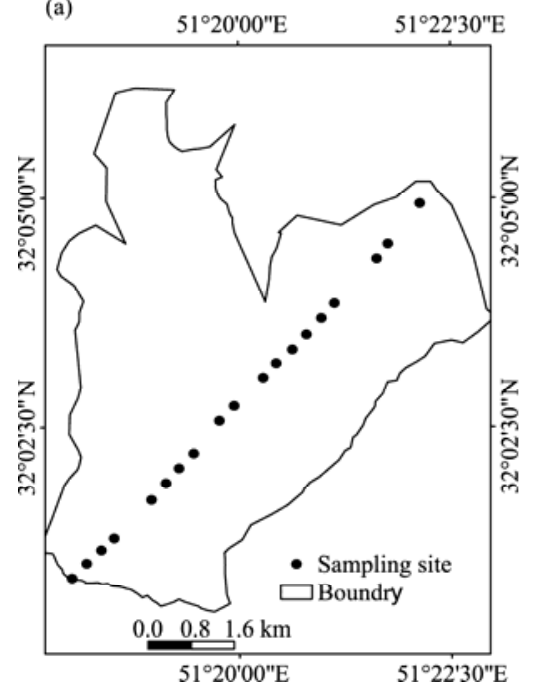

(b)

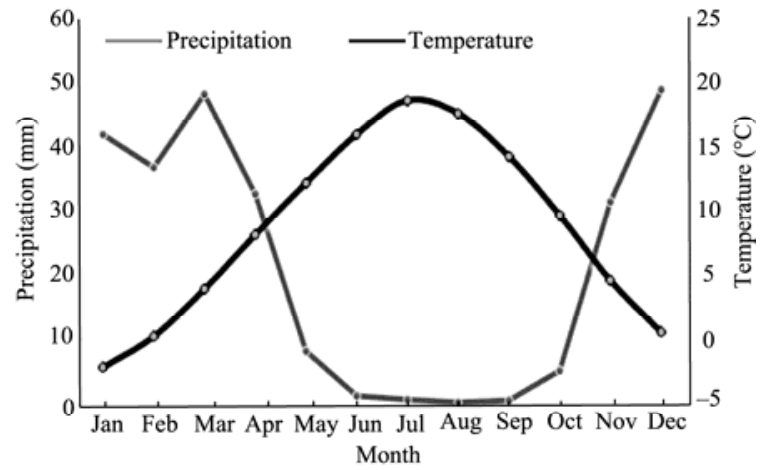

Fig. 1 Sampling sites (a) and monthly mean temperature and precipitation (b) of the study area

Table 1 Dominant plant species, their genera, families, and sub-life forms in the Marjan rangeland

\begin{tabular}{cccc}
\hline Family & Genus & Species & Sub-life form \\
\hline Poaceae & Bromus & Bromus tomentellus Boiss. & Tall grass \\
Poaceae & Festuca & Festuca ovina L. & Tall grass \\
Poaceae & Stipa & Stipa hohenackeriana Trin. \& Rupr. & Tall grass \\
Poaceae & Taeniatherum & Taeniatherum crinitum Schreb. & Short grass \\
Poaceae & Bromus & Bromus tectorum L. & Short grass \\
Poaceae & Bromus & Bromus danthoniae Trin. & Short grass \\
Chenopodiacea & Noaea & Noaea mucronata (Forssk.) & Shrub \\
Astraceae & Scariola & Scariola orientalis (Boiss.) Sojak & Shrub \\
Papilionaceae & Astragalus & Astragalus verus Olivier & Shrub \\
Papilionaceae & Astragalus & Astragalus cephalanthus DC. & Shrub \\
Papilionaceae & Astragalus & Astragalus pinetorum Boiss. & Short forb \\
Brassicaceae & Alyssum & Alyssum marginatum Steud. ex Boiss. & Short forb \\
Papilionace & Onobrychis & Onobrichis gaubae Bornm. & Short forb \\
Lamiaceae & Phlomis & Phlomis persica Boiss. & Tall forb \\
Lamiaceae & Phlomis & Phlomis olivieri Benth. & Tall forb \\
Lamiaceae & Stachys & Stachys pilifera Benth. & Tall forb \\
\hline
\end{tabular}

Cut and weight method was used to measure above-ground biomass (Bonham, 2013) at the sub-life form level. Above-ground biomass was cut in quadrats, green and photosynthetic leaves and twigs were separated from dried parts at each vegetative period. Green above-ground biomass was oven-dried at $65^{\circ} \mathrm{C}$ and finally weighed. A gridded quadrat frame of $2 \mathrm{~m} \times 2 \mathrm{~m}$ was used to accurately measure canopy cover at the sub-life form level (Shiyomi and Yoshimura, 2000). Each sides of quadrate were divided into 100 equal parts of $20 \mathrm{~cm} \times 20 \mathrm{~cm}$ as a mesh or gridded quadrate to be more precise in estimating of canopy cover (Bonham, 2013). For each sampling period only green canopy cover was measured.

2.2.2 Data analysis of modelling the relationship between canopy cover and above-ground biomass

The process of data analysis is summarized as underneath stages. At the first stage, normal 


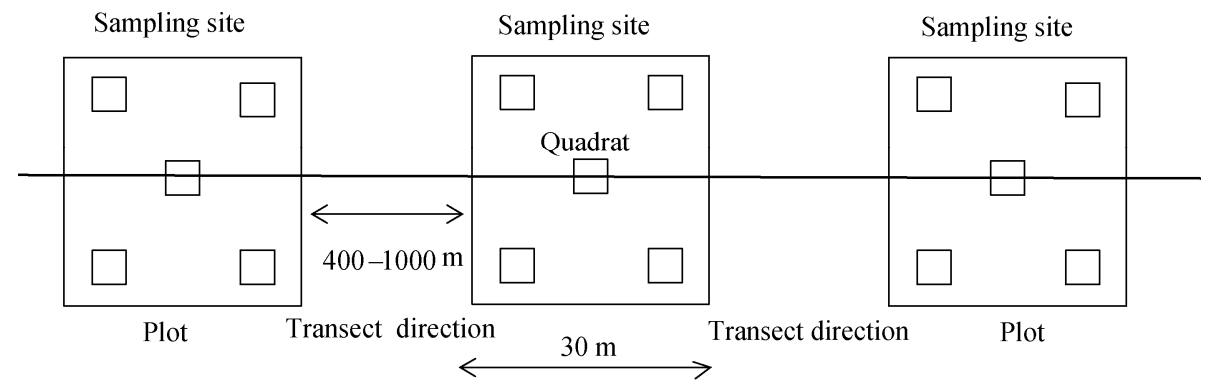

Fig. 2 Sampling design for testing the relationship between canopy cover and above-ground biomass. Schematic representation shows 3 out of the 19 sampling sites (with $400-1000 \mathrm{~m}$ intervals) along a 10-km transect. Each sampling site contains 5 quadrats of $2 \mathrm{~m} \times 2 \mathrm{~m}$ dimensions arranged with 1 centroid quadrat and the other 4 quadrats positioned 5-m away at four directional corners.

distribution of response variable (above-ground biomass) was investigated. We applied a general linear model (GLM) to test if a significant relationship between above-ground biomass and canopy cover exists and whether this relation is affected by life form and sampling date or not. In the GLM, measured above-ground biomass was regarded as the dependent variable (response variable), canopy cover as the independent covariate (predictor or explanatory variable) and sub-life form and sampling periods as fixed factors.

After testing the relationship between response and predictor variables, we fit the best regression model between dependent or response (above-ground biomass) and independent or predictor variable (canopy cover) at different sub-life forms and sampling dates. We developed linear predictive models for dependent variable of above-ground biomass based on independent variable of canopy cover using a set of $60 \%$ of randomly selected data out of all the ground sampled data (destructively sampled quadrats).

After processing the regression models, we investigated the following items that are the primary default in regression models to distinguish robustness of each predictive model: (1) Normal Distribution of Residuals Frequencies (NDRF) by normal P-P plot of standardized residuals; (2) testing a non-correlation between the residuals and the Durbin-Watson test (Durbin and Watson, 1951); (3) depicting the Stability in Variances of the Residuals (SVR) in a scatter plot where standardized residuals showed in $Y$ axis and the standard predicted (estimated response) values in $X$ axis to detect non-linearity and inequality error of variances; and (4) looking over the robustness of Linear Regression (LR) relationship between $Y$ (dependent variable) and $X$ (independent variable) by $R^{2}$ and $r$.

\subsubsection{Modelling the relationship between NDVI and above-ground biomass}

After selecting the most cloud-free and nearest acquiesced images of Landsat- 8 satellite to the sampling dates over the study area (Table 2), we applied FLAASH atmospheric correction on the images and calculated NDVI from the resulted images based on Equation 1.

$$
\mathrm{NDVI}=\frac{\mathrm{NIR}-\mathrm{RED}}{\mathrm{NIR}+\mathrm{RED}}
$$

where NIR is the reflectance in the near-infrared band; and RED is the reflectance in red band (Tucker, 1979).

The values of NDVI at sampling nodes were extracted and regressed against corresponding on field measured above-ground biomass of May to September (all sampling dates), where above-ground biomass was considered as a response variable and NDVI values as a predictor or independent variable. The primary defaults of regression models (mentioned in Section 2.2.2) were investigated to distinguish robustness of the predictive models.

Finally, a pair-sampled $t$-test was performed between derived above-ground biomass from NDVI values and on field measured above-ground biomass to determine if a statistically significant difference exists between actual and estimated above-ground biomass values (in $40 \%$ of the data that regarded as the test) for both methods of remotely sensed- and canopy 
cover-based methods. All of statistical analysis was performed with SPSS software (version 22.00).

Table 2 Landsat 8 images used for calculating vegetation indices and investigating its relation with above-ground biomass

\begin{tabular}{ccc}
\hline Designation & Date (yyyy-mm-dd) & Cloud cover (\%) \\
\hline A & $2014-05-24$ & 8 \\
B & $2014-06-25$ & 3 \\
C & $2014-08-02$ & 0 \\
D & $2014-09-19$ & 0 \\
\hline
\end{tabular}

\section{Results}

\subsection{Field measurement}

Canopy cover and above-ground biomass in all sub-life forms and sampling periods are presented in Figure 3. In total, averages of above-ground biomass and canopy cover decreased from sampling period of May to September. Shrub had the highest averages of canopy cover and above-ground biomass in all sampling periods, but canopy cover of the short forbs was only larger than that of the shrubs in May (Fig. 3). Average canopy covers of all sub-life forms were noticeably decreased from May to September unless the shrubs that slowly increased from May to June then slightly decreased from June to August and finally decreased by $1.5 \%$ from August to September. In this respect, short forbs and short grasses showed a more sever decreasing from May to September in comparison to the other sub-life forms. When above-ground biomass was concerned, the same pattern was observed, however, increasing of shrub biomass from May to June was more outstanding than that of canopy cover. Moreover, the biomass of shrubs was highest throughout all sampling periods whilst its canopy cover was slightly lower in May than that of tall grasses. Generally, we can conclude that shrubs are dominant in terms of both canopy cover and above-ground biomass in the study area. Furthermore, short grasses (i.e., Taeniatherium crinitum Schreb, Bromus tectorum L., and Bromus danthoniae Trin.) were absent in August and September, whilst tall grasses was only occurred in September (Fig. 3). Overall, above-ground biomass and canopy cover of shrubs were considerably higher than that of other sub-life forms during sampling periods. Tall forbs and short grasses showed the lowest values in this period (Fig. 4).
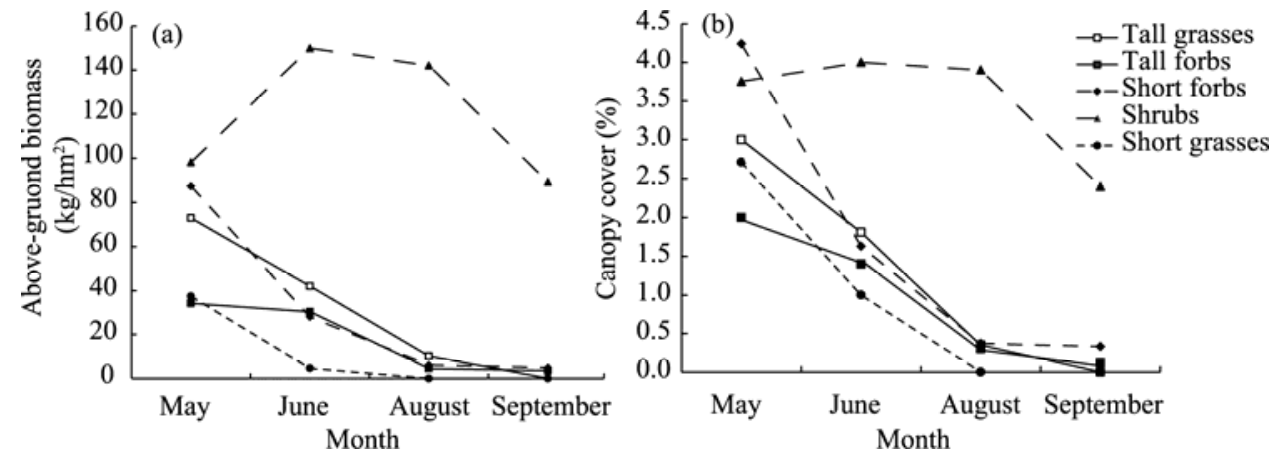

Fig. 3 Averages of above-ground biomass (a) and canopy cover (b) from field measurement in all sub-life forms and sampling periods

\subsection{GLM outputs}

Results of GLM analysis of above-ground biomass and canopy cover as well as the main effects of sub-life forms and sampling periods and their interactions are shown in Table 3. We found a significant correlation $\left(R^{2}=0.81\right)$ between above-ground biomass (response variable) and canopy cover (predictor variables) for all sub-life forms and sampling periods. Sampling periods and 


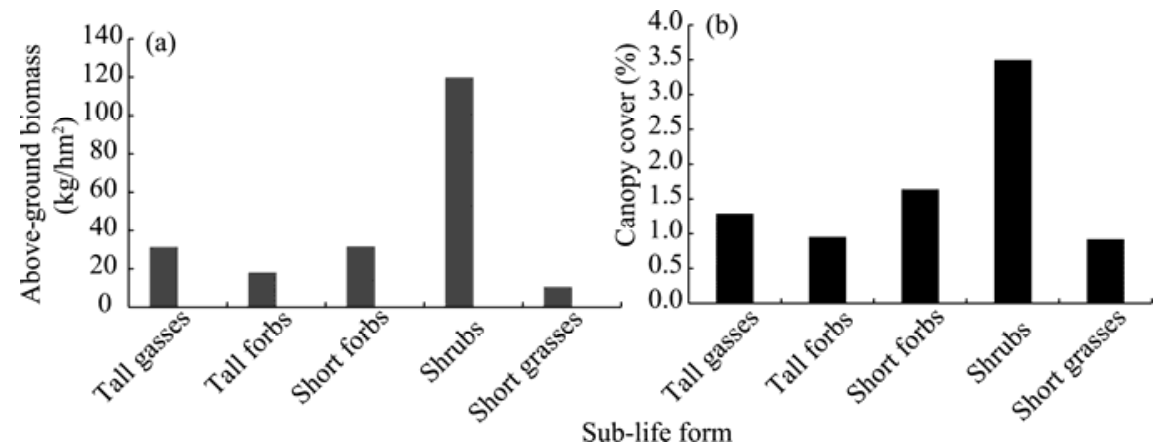

Fig. 4 Averages of total above-ground biomass (a) and canopy cover (b) during sampling periods at different sub-lifeform levels

sub-life forms as well as interaction of these two factors showed a significant effect on estimation of above-ground biomass $(P<0.05)$. A significant difference $(P<0.05)$ also found in the intercept of the linear regression of the models (Table 3 ).

Table 3 ANOVA of the general linear model (GLM) applied on dependent (above-ground biomass) and independent covariate variable (canopy cover) with main effects of sub-life form and sampling period (fixed factors) and their interactions

\begin{tabular}{|c|c|c|c|c|c|}
\hline Source & Sum of square & $d f$ & Mean square & $F$ & $P$ \\
\hline Corrected model & $1,125,513.40$ & 17 & $66,206.60$ & 171.80 & 0.001 \\
\hline Intercept & 3879.01 & 1 & 3879.01 & 10.00 & 0.002 \\
\hline Canopy cover & $735,494.30$ & 1 & $735,494.30$ & 1905.40 & 0.001 \\
\hline Life form & $43,303.90$ & 4 & $10,825.90$ & 28.04 & 0.001 \\
\hline Sampling period & $14,121.30$ & 3 & 4707.10 & 12.10 & 0.001 \\
\hline Life form $\times$ Sampling period & $17,085.70$ & 9 & 1898.40 & 4.90 & 0.001 \\
\hline Error & $255,910.30$ & 663 & 385.90 & & \\
\hline Total & $2,035,461.60$ & 681 & & & \\
\hline Corrected total & $1,381,423.70$ & 680 & & & \\
\hline
\end{tabular}

\subsection{Modelling the relationship between canopy cover and above-ground biomass}

In general, the results of linear regression in all sub-life forms and sampling periods indicated a high $R^{2}$ value (i.e., 0.71 for short grasses and 0.96 for short forbs; Table 4). Overall, shrubs had the most significant relation (mean of $R^{2}=0.91$ ), short grasses and tall grasses showed the least significant relation (mean of $R^{2}=0.78$ ), and tall forbs and short forbs lay in between with the mean $R^{2}$ values of 0.80 and 0.84 , respectively. $R^{2}$ changes from sampling periods of May to September. In total, September, May, August, and June had the highest to the lowest values of mean $R^{2}$ from $0.94,0.85,0.82$, to 0.80 , respectively. As indicated in Table 3 , all of the primary defaults of regression models were met.

\subsection{Modelling the relationship between NDVI and above-ground biomass}

Table 5 shows a linear regression between above-ground biomass (response variable) and NDVI (predictor variable). A significant relationship is also found between above-ground biomass and NDVI $(P \leq 0.05)$ with a $R^{2}$ value of 0.57 . As indicated in Table 5 , all of the primary default of regression model in this method was also met.

\subsection{Results of validity test of the models}

The results of estimated above-ground biomass from developed prediction models versus field measurements of above-ground biomass are shown in Figure 5. Results reveal that no significant $(P>0.05)$ difference is found between predicted above-ground biomass derived from developed models of canopy cover and field measurements of above-ground biomass for all sub-life forms 
and sampling periods in testing samples (Figs. 5a-e). Similarly, no significant $(P>0.05)$ difference is found between predicted total above-ground biomass derived from NDVI and measured above-ground biomass in the field (Fig. 5f).

Table 4 Developed predictive regression models between canopy cover (independent) and above-ground biomass (dependent) variables as well as the results of primary defaults in regression models

\begin{tabular}{|c|c|c|c|c|c|c|c|c|}
\hline Sampling date & Sub-life form & Equation & $R^{2}$ & NDRF & VRS & Durbin-Watson & LR & $\begin{array}{c}\text { Mean of } \\
R^{2}\end{array}$ \\
\hline \multirow{6}{*}{ May } & Tall grasses & $Y=6.3+8.03 X$ & 0.84 & $\checkmark$ & $\checkmark$ & 1.50 & $\checkmark$ & \multirow{6}{*}{0.85} \\
\hline & Tall forbs & $Y=4.33+4.39 X$ & 0.77 & $\checkmark$ & $\checkmark$ & 2.20 & $\checkmark$ & \\
\hline & Short forbs & $Y=-0.29+8.81 X$ & 0.88 & $\checkmark$ & $\checkmark$ & 1.40 & $\checkmark$ & \\
\hline & Shrubs & $Y=-0.29+11.56 X$ & 0.93 & $\checkmark$ & $\checkmark$ & 2.00 & $\checkmark$ & \\
\hline & Short grasses & $Y=4.07+3.97 X$ & 0.83 & $\checkmark$ & $\checkmark$ & 2.20 & $\checkmark$ & \\
\hline & Tall grasses & $Y=4.5+7.52 X$ & 0.78 & $\checkmark$ & $\checkmark$ & 1.60 & $\checkmark$ & \\
\hline \multirow{3}{*}{ June } & Tall forbs & $Y=-0.78+9.01 X$ & 0.75 & $\checkmark$ & $\checkmark$ & 1.65 & $\checkmark$ & \multirow{3}{*}{0.78} \\
\hline & Short forbs & $Y=6.25+3.97 X$ & 0.77 & $\checkmark$ & $\checkmark$ & 2.55 & $\checkmark$ & \\
\hline & Shrubs & $Y=-4.6+18.42 X$ & 0.91 & $\checkmark$ & $\checkmark$ & 2.00 & $\checkmark$ & \\
\hline \multirow{6}{*}{ August } & Short grasses & $Y=1.43+3.14 X$ & 0.71 & $\checkmark$ & $\checkmark$ & 1.70 & $\checkmark$ & \multirow{4}{*}{0.80} \\
\hline & Tall grasses & $Y=-0.6+12.14 X$ & 0.73 & $\checkmark$ & $\checkmark$ & 1.60 & $\checkmark$ & \\
\hline & Tall forbs & $Y=1.77+4.17 X$ & 0.80 & $\checkmark$ & $\checkmark$ & 2.40 & $\checkmark$ & \\
\hline & Short forbs & $Y=1.51+3.53 X$ & 0.75 & $\checkmark$ & $\checkmark$ & 2.00 & $\checkmark$ & \\
\hline & Shrubs & $Y=-1.86+17.92 X$ & 0.91 & $\checkmark$ & $\checkmark$ & 1.70 & $\checkmark$ & \multirow[b]{2}{*}{0.90} \\
\hline & Tall forbs & $Y=-1.7+12.81 X$ & 0.88 & $\checkmark$ & $\checkmark$ & 1.82 & $\checkmark$ & \\
\hline \multirow{2}{*}{ September } & Short forbs & $Y=1.39+3.26 X$ & 0.96 & $\checkmark$ & $\checkmark$ & 1.70 & $\checkmark$ & \\
\hline & Shrubs & $Y=-0.27+16.72 X$ & 0.87 & $\checkmark$ & $\checkmark$ & 2.23 & $\checkmark$ & \\
\hline
\end{tabular}

Note: $Y$, above-ground biomass $X$, canopy cover; NDRF, Normal Distribution of Residuals Frequencies; SRV, Stability of Residuals Variances; Non-correlation between the residuals: $1.50<$ Durbin-Watson $<2.50$; LR, linear relationship between dependent and independent variables. $\checkmark$ indicates that primary default of regression model was met. It should be noted that some of the sub-life forms were absent in some sampling periods.

Table 5 Linear model between NDVI and total above-ground biomass

\begin{tabular}{ccccccc}
\hline Equation & $R^{2}$ & NDRF & SVR & Durbin-Watson & LR & Sig \\
\hline$Y=-47.64+1273.06 \times$ NDVI & 0.57 & $\checkmark$ & $\checkmark$ & $\checkmark$ & $\checkmark$ & 0.00 \\
\hline
\end{tabular}

Note: NDRF, Normal Distribution of Residuals Frequencies; SVR, Stability of Residuals Variances; Non-correlation between the residuals: $1.50<$ Durbin-Watson $<2.50$; LR, linear relationship dependent and independent variables. $\checkmark$ indicates that primary default of regression model was met.

\subsection{Above-ground biomass images derived from NDVI and measured values}

The above-ground biomass maps obtained from the best fit of linear models between NDVI and total above-ground biomass at different sampling periods are shown in Figure 6. As indicated in these images, NDVI values as well as above-ground biomass generally declined from May to September. The highest values of above-ground biomass observed in May ranged from 300 to 600 $\mathrm{kg} / \mathrm{hm}^{2}$ (Fig. 6a), while the lowest values observed in September were between 20 and 140 $\mathrm{kg} / \mathrm{hm}^{2}$ (Fig. 6e).

\section{Discussion}

In this study, we investigated that whether canopy cover could be an appropriate explanatory variable for estimating above-ground biomass in an arid steppe rangeland. The results were compared with the remotely sensed data. As shown in Figure 4, the results from the measurements in the field indicated that the averages of canopy cover and the above-ground biomass decreased from $15.70 \%$ to $2.85 \%$ and from 330.3 to $97.5 \mathrm{~kg} / \mathrm{hm}^{2}$ from May to September, respectively. Declining vegetation from the end of May in the Mediterranean arid steppe regions is a normal 

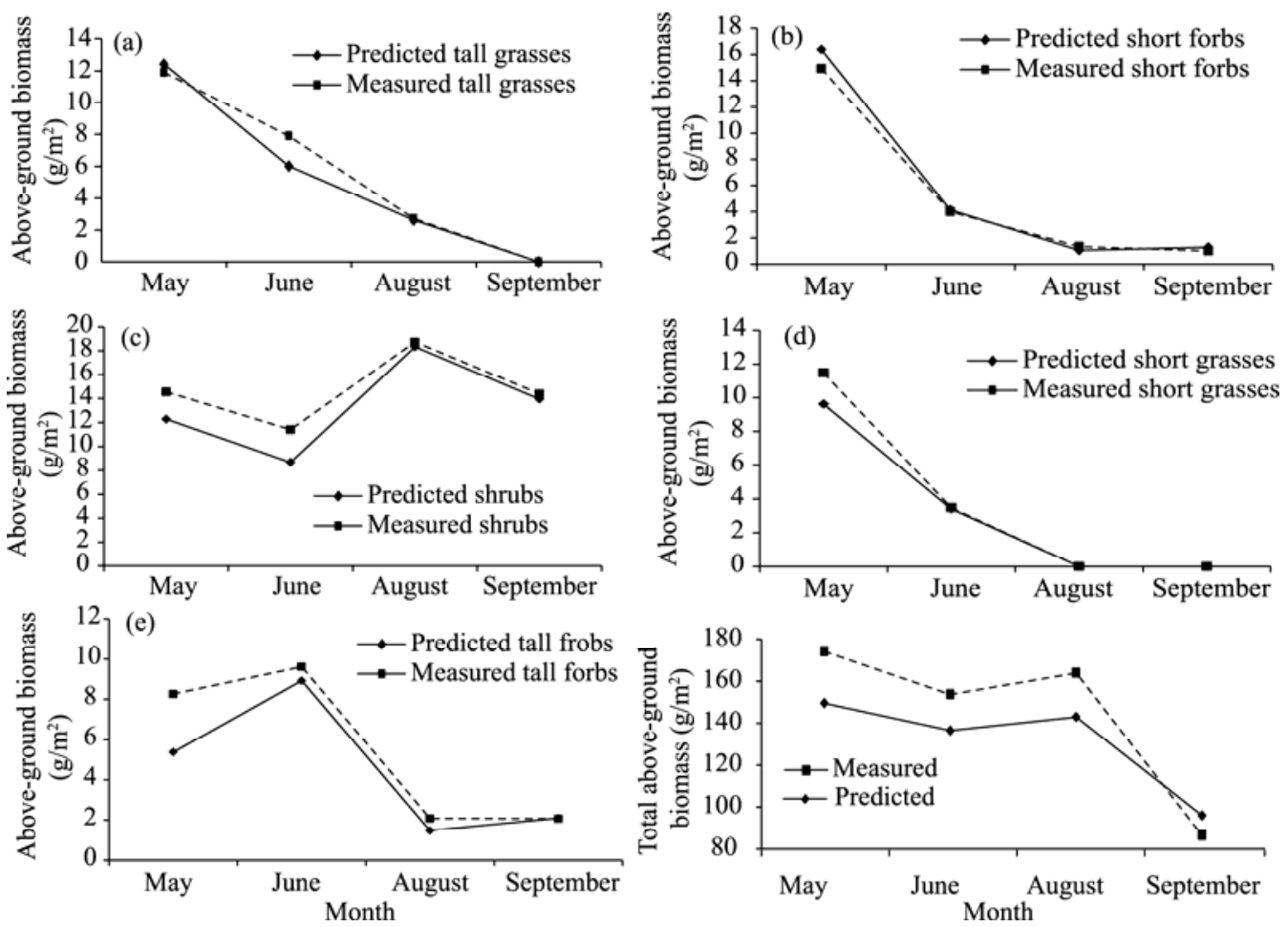

Fig. 5 Predicted above-ground biomass and total above-ground biomass from developed models versus measured above-ground biomass in the field at different sub-life forms and sampling periods using testing data. There is no significant difference between predicted and measured values $(P>0.05)$.

phenomenon due to the lack of rainfall during summer season (Fig. 1b). In the study area, canopy cover and above-ground biomass of shrubs are dominated in comparison to the other sub-life forms (Figs. 3 and 4). The fluctuation of this life form in above-ground biomass and more specifically in canopy cover is lower than those of any other sub-life forms. Namely, other sub-life forms significantly decreased in both canopy cover and above-ground biomass from May to September (Fig. 3). In contradict to that, the shrub life form tended to increase from May to June and August and finally decreased to September. The growth season of shrub species (e.g., Astragalus verus Olivier and Astragalus cephalanthus DC.) starts with a significant delay compared to other life forms. The growth season of short forbs (mostly ephemerals) grows up earlier than those of tall grasses. Intrinsically, short forbs (e.g., Astragalus pinetorum Boiss., Astragalus effuses Bunge, Allysum marginatum Steud. ex Boiss., and Onobrychis gaubae Bornm in Table 1) are mostly replaced by other sub-life forms during the growth season, especially shrubs and tall grasses that had more stability in above-ground biomass. Although, short forbs dominated the first sampling course, still they seriously declined in above-ground biomass and canopy cover in comparison to the shrubs and tall grasses during the second and third sampling periods. Moreover, we found a few short forbs in the last sampling periods. However, tall forbs and short grasses were absent in the last sampling period (Figs. 3 and 4).

As shown in Table 3, a significant relation $(P<0.05)$ was found between above-ground biomass (response variable) and canopy cover (predictor variable), suggesting that canopy cover is an instructive explanatory variable for estimating above-ground biomass. Regardless of aforementioned fluctuation in biomass and canopy cover of different sub-life forms which is a commonplace phenomenon in arid and semi-arid rangeland of the Mediterranean type, the result of Table 3 indicates that above-ground biomass can accurately be predicted by canopy cover. Montès et al. (2004), Flombaum and Sala (2007) and Arzani et al. (2008) also found that canopy cover is an appropriate proxy for biomass estimation. Results from Table 4 and Figure 5 also demonstrate the hypothesize that canopy cover properly describes the above-ground biomass 

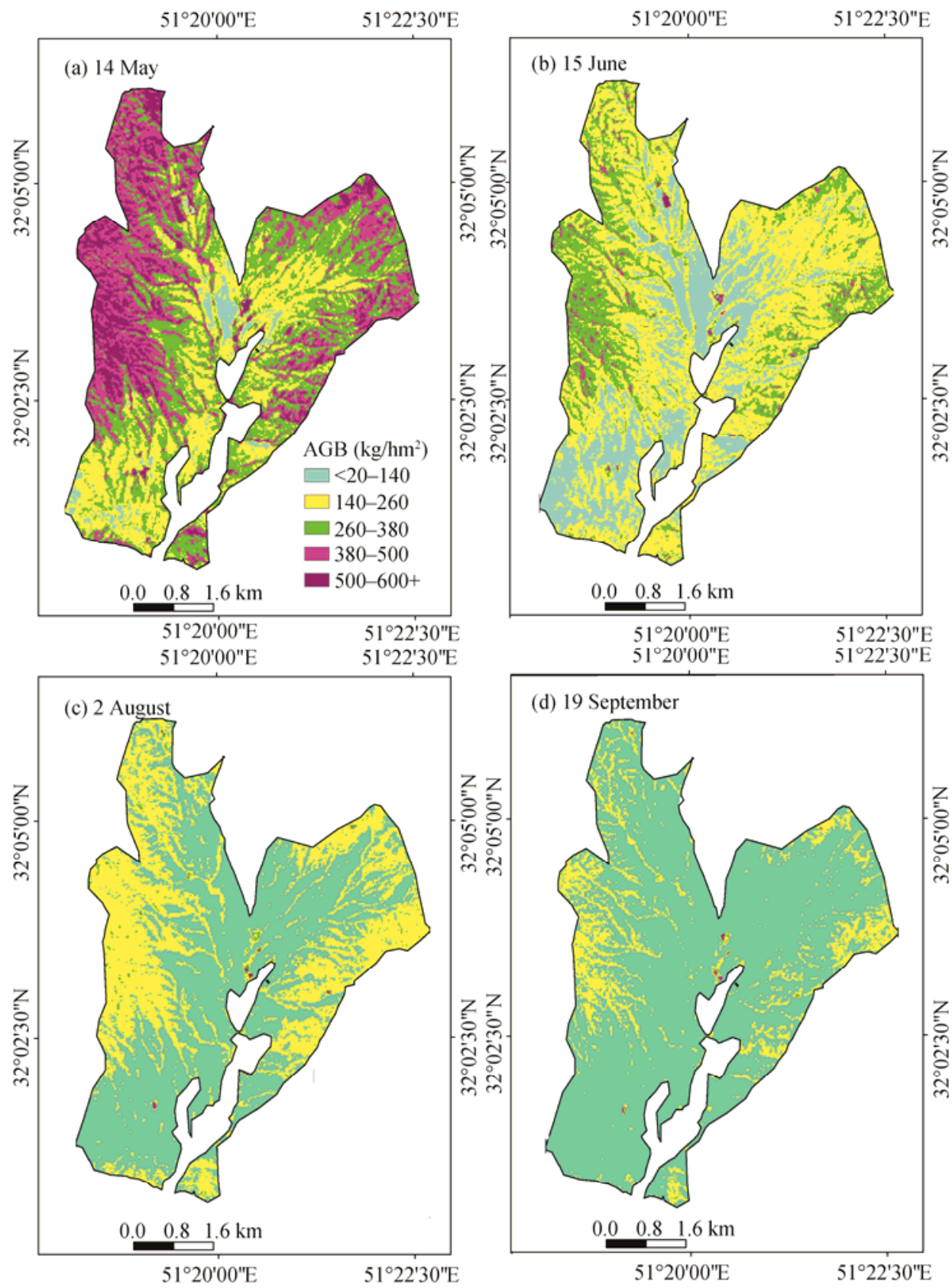

Fig. 6 Above-ground biomass (AGB) maps at different sampling periods derived from calculated NDVI. The white area in the study area is the other land uses.

in arid rangeland where canopy cover is distinct and sparse. Thereby, this indirect method of estimating plant biomass that is based on an easier-to-measure attribute of canopy cover is vital for regularly tuning of grazing pressure. This method is quite faster and less labor intensive to estimate than destructive method of clipping and weighting that endangers rare species.

Although a high correlation was found between above-ground biomass and canopy cover, the data of different sampling dates and sub-life forms should not be lumped together to make one predictive model due to a significant effect of sampling dates and sub-life forms, as well as, their interaction on estimation of above-ground biomass $(P<0.05)$ by canopy cover (Table 3$)$. This is quite dangerous in different growth stages, wherein the height and volume changes are perceptible. Therefore, we emphasize the effects of both sampling periods and vegetative forms 
on the relationship between above-ground biomass and canopy cover. Some literature also highlighted the effects of climate change and grazing impacts on the above-ground biomass and canopy cover relationships (Hughes et al., 1987; N'avar et al., 2004, Foroughbakhch et al., 2005; Arzani et al., 2008; Arzani et al., 2011). We do not recommend the use of predictive models of mid-growth stages (June) for other stages (see Tables 2 and 3). Moreover, a significant difference $(P<0.05)$ was also found in the intercept of the GLM (Table 2), enforcing us to use different prediction models for sampling dates and sub-life forms. The significant difference in intercept of GLM might originate from intrinsic variation in above-ground biomass and canopy cover of different growth stages (sampling dates) of various sub-life forms.

Even though the correlation between canopy cover and above-ground biomass is significant in all sampling periods ( $R^{2}$ ranging from 0.71 to 0.96$)$, still shrubs tended to show a more stable and higher relationship between its canopy cover and above-ground biomass (mean of $R^{2}=0.90$ ). This is particularly when they are being compared to short grasses that showed the least significant relationship (mean of $R^{2}=0.77$ ) (Table 4 ). This might be due to a more distinguished canopy cover, and a higher volume of shrubby species and a more stable and homogenous outer-form of shrub sub-life form in contrast to the others. According to our findings, when the plants have spent their maximum growth and greenness, progressing towards dehydration; the correlation between canopy cover and above-ground biomass slightly reduced (Table 4). The increasing trend of significance that is found from sampling period of August to September might be due to increasing shrub life form from early vegetative growth to maturing as well as diminishing short grasses that are hard to be predicted. The high correlation at the end of growth season in some sub-life forms, such as tall forbs, might be due to the presence and regrowth of new species that are green and pass their early and middle periods of growth stages. Other research also found that the species-specific allometric models fit the data well to predict total above-ground biomass for each species, but the above-ground biomass of tree shaped species was significantly predicted by a single predictor. Moreover, shrubs with a tall stem and an umbrella-like canopy structure (e.g., Acacia mellifera (Vahl) Benth) were most accurately predicted by use of a combination of both circumference of the stem at ankle height and canopy volume (Hasen Yusuf et al., 2013). A higher correlation found for shrubby species in our finding is in line with Hasen Yusuf et al. (2013), who approving a more reliable predicting of shrub species than the others.

In this study, we found no significant difference between the estimation of above-ground biomass by using NDVI data and ground sampling in the field (Fig. 6). Meanwhile, a relatively poor relation between above-ground biomass and NDVI at the sub-life form level was found. Ghorbani et al. (2017) also found a significant but no strong relationship $\left(R^{2}=0.23,0.29\right.$ and 0.153 for grasses, forb and shrubs, respectively) between above-ground biomass and NDVI in Sabalan rangelands of Iran. This might be due to the effect of factors such as soil reflectance in arid and semi-arid regions on the received signals by the sensors of satellites.

Since no significant difference between above-ground biomass estimates using canopy cover and field measurements at different sub-life forms and sampling periods (Fig. 5) was found, it can be concluded that canopy cover is an appropriate explanatory variable for predicting above-ground biomass. Still the sampling periods and sub-life forms should be taken into account due to morphological variations during different phenological stages and instinct variation of sub-life forms canopy cover. Since the term canopy is referring to the extent of the outer layer of leaves of an individual plant species or a group of plants that normally blocks light to the ground, its structure, organization, or spatial arrangement (three-dimensions) might differ on phenological stages from early vegetative growth to maturity. This might be the main reason of significant effect of sub-life form and sampling date upon the relationship between predictor and response variables (Table 3). Recent research suggests that canopy cover is a reliable predictor variable and an appropriate alternative indicator for estimating above-ground biomass at the sub-life form level (Ebrahimi, 2017); this potential generally can help to estimate rangelands biomass and grazing capacity as a non-destructive method (Gholami baghi et al., 2013).

The results revealed that despite the capability of remotely sensed images for estimating above-ground biomass by means of NDVI (Figs. 5 and 6; Tables 4 and 5), canopy cover is a more 
straightforward and reliable indicator for predication of above-ground biomass not only at the community level but also at the sub-life form level ( $R^{2}$ ranging from 0.75 to 0.96$)$. Therefore, we recommend the use of this nondestructive, fast, and reliable method for estimating above-ground biomass in arid and semi-arid rangelands.

\section{Conclusions}

Due to spare distribution of vegetation in arid and semi-arid rangelands, estimation of above-ground biomass by remotely sensed data is not feasible, however, using canopy cover to estimate above-ground biomass especially the shrubby species is highly recommended for its non-destructive. According to our research, there is a strong relationship between canopy cover and above-ground biomass. Therefore, estimation of above-ground biomass is accurately possible using canopy cover at the sub-life form level. However, given the effects of growth season and sampling periods on this relationship, developing different models to predict above-ground biomass based on explanatory variable of canopy cover is needed.

\section{Acknowledgements}

We would like to express our thanks to the anonymous reviewers and Dr. Mansour MESDAGHI for their generous and insightful suggestions, which certainly improved the quality of this paper. The authors wish to thank Mrs. Maryam AHMADI, Mr. Babak CHABOK and Mr. Jahangir NAREHI for their assistance in the field work.

\section{References}

Adler P B, Milchunas D G, Lauenroth W K, et al. 2004. Functional traits of graminoids in semi-arid steppes: a test of grazing histories. Journal of Applied Ecology, 41(4): 653-663.

Anderson E W. 1986. A guide for estimating cover. Rangelands, 8(5): 236-238.

Arzani H, Basiri M, Dehdari S, et al. 2008. Relationships between canopy cover, foliage cover and basal cover with production. Iranian Journal of Natural Resources, 61(3): 763-773.

Arzani H, Dehdari S, King G. 2011. Models for estimating range production by cover measurement. Iranian Journal of Range and Desert Reseach, 18(1): 1-16.

Brinkmann K, Dickhoefer U, Schlecht E, et al. 2011. Quantification of aboveground rangeland productivity and anthropogenic degradation on the Arabian Peninsula using Landsat imagery and field inventory data. Remote Sensing of Environment, 115(2): 465-474.

Bonham C D. 2013. Measurements for Terrestrial Vegetation. New York: John Wiley and Sons, 260.

Caprioli M, Figorito B, Tarantino E. 2006. Radiometric normalization of Landsat ETM+ data for multitemporal analysis. In: Proceedings of the ISPRS Commission VII Mid-Term Symposium on Remote Sensing: From Pixels to Processes. Enschede, The Netherlands, 8-11 May 2006.

Drake J B, Knox R G, Dubayah R O, et al. 2003. Above-ground biomass estimation in closed canopy Neotropical forests using lidar remote sensing: factors affecting the generality of relationships. Global Ecology \& Biogeography, 12(2): 147-159.

Di Bella C, Faivr R, Ruget F, et al. 2005. Using VEGETATION satellite data and the crop model STICS-Prairie to estimate pasture production at the national level in France. Physics and Chemistry of the Earth, Parts A/B/C, 30(1-3): 3-9.

Durbin J, Watson G S. 1951. Testing for serial correlation in least squares regression.II. Biometrika, 38(1-2): 159-178.

Du Plessis W P. 1999. Linear regression relationships between NDVI, vegetation and rainfall in Etosha National Park, Namibia. Journal of Arid Environments, 42(4): 235-260.

Ebrahimi A, Bossuyt B, Hoffmann M. 2008. Effects of species aggregation, habitat and season on the accuracy of double sampling to measure herbage mass in a lowland grassland ecosystem. Grass and Forage Science, 63(1): 79-85.

Ebrahimi A. 2017. Effect of sampling groups and life forms on relationship between above-ground biomass and canopy cover. Journal of Range and Watershed Management, 70(1): 19-30.

Etienne M. 1989. Non destructive methods for evaluating shrub biomass: a review. Acta oecologica Oecologia applicata, 10: 115-128. (In French)

Flombaum P, Sala O E. 2007. A non-destructive and rapid method to estimate biomass and aboveground net primary production in arid environments. Journal of Arid Environments, 69(2): 352-358. 
Foroughbakhch R, Reyes G, Alvarado-Vázquez M A, et al. 2005. Use of quantitative methods to determine leaf biomass on 15 woody shrub species in northeastern Mexico. Forest Ecology and Management, 216(1-3): 359-366.

Frank T D, Tweddale S A, Lenschow S J. 2005. Non-destructive estimation of canopy gap fractions and shrub canopy volume of dominant shrub species in the Mojave desert. Journal of Terramechanics, 42(3-4): 231-244.

Ji L, Wylie B K, Nossov D R, et al. 2012. Estimating aboveground biomass in interior Alaska with Landsat data and field measurements. International Journal of Applied Earth Observation and Geoinformation, 18: 451-461.

Guevara J C, Gonnet J M, Estevez O R. 2002. Biomass estimation for native perennial grasses in the plain of Mendoza, Argentina. Journal of Arid Environments, 50(4): 613-619.

Gholami baghi N, Sepehri A, Barani H, et al. 2013. Estimating plant biomass by using non-destructive parameters in arid regions (case study: Inche-Broun Winter Rangelands, Golestan, Iran). Journal of Rangeland Science, 3(4): $295-301$.

Ghorbani A, Pournemati A, Panahandeh M. 2017. Estimating and mapping Sabalan rangelands aboveground phytomass using Landsat 8 images. Iranian Journal of Range and Desert Research, 24(1): 165-180.

Glenn N F, Neuenschwander A, Vierling L A, et al. 2016. Landsat 8 and ICESat-2: Performance and potential synergies for quantifying dryland ecosystem vegetation cover and biomass. Remote Sensing of Environment, 185: 233-242.

Hasen Yusuf M, Treydte A C, Abule E, et al. 2013. Predicting aboveground biomass of woody encroacher species in semi-arid rangelands, Ethiopia. Journal of Arid Environments, 96: 64-72.

Hughes H G, Varner L W, Blackenship L H. 1987. Estimating shrub production from plant dimension. Journal of Range Management, 40(4): 367-369.

Li Q Y, Tuo D B, Zhang L Z, et al. 2014. Impacts of climate change on net primary productivity of grasslands in Inner Mongolia. The Rangeland Journal, 36(5): 493-503.

Lu D, Mausel P, Moran E F, et al. 2004. Change detection techniques. International Journal Remote Sensing, 25(12): 2365-2407.

Ke Y, Im J, Lee J, et al. 2015. Characteristics of Landsat 8 OLI-derived NDVI by comparison with multiple satellite sensors and in-situ observations. Remote sensing of environment, 164: 298-313.

Liu S L, Su X K, Dong S K, et al. 2015. Modeling aboveground biomass of an alpine desert grassland with SPOT-VGT NDVI. GIScience \& Remote Sensing, 52(6): 680-699.

Migliavacca M, Galvagno G, Cremonese E, et al. 2011. Using digital repeat photography and eddy covariance data to model grassland phenology and photosynthetic $\mathrm{CO}_{2}$ uptake. Agricultural and Forest Meteorology, 151(10): 1325-1337.

Mokhtariasl A, Mesdaghi M. 2008. Estimating production of Atriplex veruciferum and Salsola dendroides by using canopy cover and volume parameters. Pajouhesh-Va-Sazandegi, 20(4): 141-147.

Montès N, Ballin, C, Bonin G, et al. 2004. A comparative study of aboveground biomass of three Mediterranean species in a post-fire succession. Acta Oecologica, 25(1-2): 1-6.

Montès N. 2009. A non-destructive method to estimate biomass in arid environments: A comment on Flmbaun and Sala (2007). Journal of Arid Environments, 73(6-7): 599-601.

Návar J, Méndez E, Nájera A. 2004. Biomass equations for shrub species of Tamaulipan thornscrub of North-eastern Mexico. Journal of Arid Environments, 59(4): 657-674.

Olofsson J, Kitti H, Rautiainen P, et al. 2001. Effects of summer grazing by reindeer on composition of vegetation, productivity and nitrogen cycling. Ecography, 24(1): 13-24.

Pordel F. 2015. Evaluation of spatio-temporal changes of phytomass and canopy cover of Mrajan rangeland, Boroujen using Landsat remotely sensed data. MSc Thesis. Shahrekord University: Faculty of Natural Resources and Earth Science Department of Rangeland and Watershed Management.

Porter T F, Chen C, Long J A, et al. 2014. Estimating biomass on CRP pastureland: A comparison of remote sensing techniques. Biomass and Bioenergy, 66: 268-274.

Radloff F G T, Mucina L. 2007. A quick and robust method for biomass estimation in structurally diverse vegetation. Journal of Vegetation Science, 18(5): 719-724.

Sala O E, Austin A T. 2000. Methods of estimating aboveground net primary productivity. In: Sala O E, Jackson R B, Mooney $\mathrm{H}$ A, et al. Methods in Ecosystem Science. New York: Springer, 31-43.

Shiyomi M, Yoshimura J. 2000. Measures of spatial heterogeneity for species occurrence or disease incidence with finite-counts. Ecological Research, 15(1): 13-20.

Snyman H. 1998. Dynamics and sustainable utilization of rangeland ecosystems in arid and semi-arid climates of southern Africa. Journal of Arid Environments, 39(4): 645-666.

Tackenberg O. 2007. A new method for non-destructive measurement of biomass, growth rates, vertical biomass distribution and dry matter content based on digital image analysis. Annals of Botany, 99(4): 777-783. 
Tahmasebi P, Ebrahimi A A, and Yarali N A. 2012. The most appropriate quadrate size and shape for determining some characteristics of a semi-steppic rangeland. Journal of Range and Watershed Management, 65(2): 203-216. (In Persian)

Thursby G B, Chintala M M, Stetson D, et al. 2002. A rapid, non-destructive method for estimating aboveground biomass of salt marsh grasses. Wetlands, 22(3): 626-630.

Tucker C J. 1979. Red and photographic infrared linear combinations for monitoring vegetation. Remote Sensing of Environment, 8(2): 127-150.

Wang M, Overland J E. 2004. Detecting arctic climate change using KÖppen climate classification. Climatic Change, 67(1): 43-62.

Yang H T, Wang Z R, Tan H J, et al. 2017. Allometric models for estimating shrub biomass in desert grassland in northern China. Arid Land Research and Management, 31(3): 283-300.

Zhu X L, Liu D S. 2015. Improving forest aboveground biomass estimation using seasonal Landsat NDVI time-series. ISPRS Journal of Photogrammetry and Remote Sensing, 102: 222-231. 